\title{
Ergenler için Yeterlik Algısı Ölçeğinin (YAÖ) Geliştirilmesi*
}

\section{Developing Perceived Competence Scale (PCS) for Adolescents}

\author{
Arif ÖZER** Dilek GENÇTANIRIM KURT*** Seval KIZILDAĞ***** \\ Selen DEMIRTAŞ ZORBAZ***** Fatma ARICI ŞAHİN****** \\ Tülin ACAR $* * * * * * *$ Tuncay ERGENE********
}

\section{$\ddot{O} \mathbf{z}$}

Bu çalışmada, lise öğrencilerinin yeterlik algılarını ölçmek amacıyla Yeterlik Algısı Ölçeği geliștirilmiştir. Ölçek geliştirme çalışmaları üç ayrı örneklem üzerinde gerçekleştirilmiştir. Ankara ilindeki liselerde 2011 - 2012 eğitim ve öğretim yılında okullarına devam eden 372 öğrenci betimleyici faktör analizi, 668 öğrenci doğrulayıc1 faktör analizi ve 75 öğrenci test tekrar test güvenirlik çalışmalarına katılmışlardır. İç tutarlık katsayıları (Cronbach ve tabakalı $\alpha$ ) her grup için ayrı ayrı hesaplanmıştır. Verilerin çözümlenmesinde Factor 8.02 ve LISREL 8.70 paket programları kullanılmıştır. Analiz sonuçlarına göre; betimleyici ve doğrulayıcı faktör analizlerinin yapıldığı örneklemlerde iç tutarlık (Cronbach $\alpha$ ) katsayıları akademik yeterlik boyutu için sırasıyla $.90-.93$, sosyal yeterlik boyutu için $.82-.86$ 'dır. Ölçeğin bütünü için iç tutarlık (tabakalı $\alpha$ ) katsayısı ise .91 olarak hesaplanmıştır. Test tekrar test güvenirlikleri için düzeltilmiş korelasyon katsayıları (r) sosyal yeterlik için .94; akademik yeterlik için .90 'dır. Faktör analizleri sonucunda elde edilen regresyon ağırlıkları ve genel uyum katsayılarına ek olarak, benzeme (convergent) ve ayırma (discriminant) geçerliklerine ilişkin bulgular yeterliğin, akademik (16 madde) ve sosyal (14 madde) olmak üzere iki alt boyutta (toplam 30 madde) ele alınabileceğini göstermektedir.

Anahtar Kelimeler: Algılanan yeterlik, akademik yeterlik, sosyal yeterlik, benzeme geçerliği, ayırma geçerliği

\begin{abstract}
In this study, Perceived Competence Scale was developed to measure high school students' perceived competence. Scale development process was verified on three different samples. Participants of the research are some high school students in 2011-2012 academic terms from Ankara. Participants' numbers incorporated in exploratory factor analysis, confirmatory factor analysis and test-retest reliability are respectively as follows: 372, 668 and 75. Internal consistency coefficients (Cronbach's and stratified $\alpha$ ) are calculated separately for each group. For data analysis Factor 8.02 and LISREL 8.70 package programs were used. According to results of the analyses, internal consistency coefficients $(\alpha)$ are $.90-.93$ for academic competence, $.82-.86$ for social competence in the samples that exploratory and confirmatory factor analysis performed. For the whole scale internal consistency coefficient (stratified $\alpha$ ) is calculated as .91. As a result of test-retest reliability, adjusted correlation coefficients (r) are .94 for social competence and .90 for academic competence. In addition to fit indexes and regression weights obtained from factor analysis, findings related convergent and discriminant validity indicate that competence can be addressed in two dimensions which are academic (16 items) and social (14 items).
\end{abstract}

Keywords: Perceived competence, academic competence, social competence, convergent validity, discriminant validity

\footnotetext{
* Bu makale, TUBİTAK tarafindan desteklenen Prof. Dr. Tuncay Ergene'nin yürütücülüğünü yaptığ1 "Lise Öğrencilerinde Riskli Davranışların İncelenmesi” başlıklı ve 110K430 numaralı SOBAG projesinin bir kısmından oluşturulmuştur. Dr. Tuncay ERGENE, Boston Childen's Hospital'da bulunan ve Princible Investigator (PI): Kerim M. Munir, MD, MPH, DSC.'in olduğu NIMH ICORTHA Fogarty International Mental Health and Developmental Disabilities (MH/DD) Research Training Program'1 (D43TW05807) tarafından desteklenmektedir.

**Doç. Dr., Hacettepe Üniversitesi, Eğitim Fakültesi, Ankara-Türkiye, arifozer@hacettepe.edu.tr: ***Yard. Doç. Dr., Ahi Evran Üniversitesi, Eğitim Fakültesi, Kırşehir - Türkiye, digenc@gmail.com ****Arş. Gör. Dr., Adıyaman Üniversitesi, Eğitim Fakültesi,Adıyaman-Türkiye, e-posta: sevalpdr@gmail.com *****Arş. Gör., Hacettepe Üniversitesi, Eğitim Bilimleri Enstitüsü,Ankara-Türkiye, e-posta: selenpdr@gmail.com ******Arş. Gör., Hacettepe Üniversitesi, Eğitim Bilimleri Enstitüsü,Ankara-Türkiye, e-posta: farici@ hacettepe.edu.tr *******Arş. Gör., Hacettepe Üniversitesi, Eğitim Fakültesi,Ankara-Türkiye e-posta: tulina@ hacettepe.edu.tr ********Prof. Dr., Hacettepe Üniversitesi, Eğitim Fakültesi,Ankara-Türkiye e-posta: ergene@ hacettepe.edu.tr
} 


\section{GİRIŞ}

Son dönemde Psikolojik Danışma ve Rehberlik alanında ergen ve çocuklarla yapılan çalışmalarda riskli davranışların sıklıkla konu edinildiği dikkat çekmektedir. Bu durumdaki artışın temel nedeni ise bu tür davranışların nasıl önlenebileceği sorusuna yanıt vermektedir. Dolayısıyla alanda çalışan profesyonellerin önemle üzerinde durduğu bir konu da riskli davranışlara ilişkin koruyucu faktörlerin belirlenmesidir. Çoğunlukla riskli davranışlarla çalışan araştırmacılar çocuklarda ve ergenlerde riskli davranışlarla baş etmede akademik ve sosyal yeterlik alanları üzerinde durmakta; bu özelliklerin koruyucu bir faktör olduğunu dile getirmektedirler (Achenbach ve Edelbrock, 1979; Achenbach ve Zigler, 1963; Achenbach ve McConaugy, 1987). Bu bağlamda öncelikle sosyal ve akademik olmak üzere iki boyutta incelenen yeterliğin, çocuk ve ergenlerin ruh sağlı̆̆ 1 , sosyal ve kişisel gelişimi açısından koruyucu faktör olduğu düşünülebilir.

Akademik yeterlik, literatürde çoğunlukla öğretmenlerin verdikleri ödev ve yaptıkları sınavlara göre ölçülmektedir ancak akademik yeterlik öğrencilerin akademik performanslarından daha fazlasını ifade etmektedir. Başka bir ifade ile akademik yeterliğin sadece başarı ile ölçülmesi ya da başarı ile açıklanması mümkün görülmemektedir, çünkü akademik yeterlilik performanstan çok daha fazlasını içeren bir kavramdır. Anderman ve Midgley (1997) öğrencilerin sadece kendi yeteneklerini değerlendirmenin ötesinde, güçlük derecesine bağlı olarak derslerdeki yaptıklarını değerlendirerek akademik yeterlik algılarını oluşturduklarını ifade etmektedirler. Dolayısıyla bu noktada ölçülen başarıdan çok çocuk ya da ergenin kendisini o konuda nasıl bulduğu önem kazanmaktadır. Akademik yeterliğe sahip çocuk ya da ergenlerin daha mutlu oldukları ve yeterlik algıları ile benlik saygılarının daha yüksek olduğu ileri sürülmektedir (Blechman, Tinsley, Carella ve McEnroe, 1985). Akademik yeterlik algısının düşük olması ise, genel olarak problem çözme, sonuçları hakkında başarıya ilişkin işlevsel olmayan nedensel çıkarımlar ve zayıflatılmış başarı amaçlarıyla ilişkilidir (Phillips, 1984). Parsons (1982) çocukların yeteneklerine ilişkin benlik kavramlarını geçmiş başarılarından çok, gelecek ders planları, beklentileri ve değerlerinin belirlediğini ifade etmektedir. Harter (1984) düşük yeterlik algısına sahip çocuk ve ergenlerin zorlu görevlerden kaçındıklarını belirtmektedir. Bu bilgiler 1şığında akademik yeterlik algısı yüksek olan öğrencilerin dersleri anlamakta ve katılmakta zorlanmadıkları, okul dışında da derslerle uğraşmaktan zevk aldıkları, akademik ortalamalarını ölçüt almadan başarılarını değerlendirebildikleri, ödevlerini yapabilme potansiyeline sahip ve yeteneklerinin farkında oldukları söylenebilir. Akademik yeterlik sadece bireyin akademik hayatını değil, sosyal ve duyuşsal birtakım özelliklerini de etkilemektedir. Örneğin yapılan bir çalışmada (Ryan, Gheen ve Midgley, 1998) öğrencilerin sahip olduğu akademik yeterlikleri ile yardım aramadan kaçınma arasında negatif bir ilişki bulunmuştur. Bu durum ergenlerin akademik alanda kendilerini yeterli bulmalarının kişisel ve sosyal gelişimleri üzerinde de olumlu etkileri olabileceğini ortaya koymaktadır. Bu bağlamda da sosyal ve psikolojik bir takım risklerden ya da olumsuzluklardan ergenleri korumaktadır.

Yeterliğin diğer bir boyutu olan sosyal yeterlik ise, bir bireyin sosyal çevresi ile başa çıkmadaki genel eğiliminin göstergesi olarak anlaşılabilir. Ayrıca araştırmacılar akademik ve sosyal yeterliliğin birbirini tamamlayan iki faktör olduğunu belirtmektedirler (Wentzel, 1993). Sosyal yeterlik hem bireyin edindiği bilgileri kullanarak uygun davranışı seçmesi hem de bunları değişen sosyal çevrede kişisel amaçlarına yönelik kullanmasından oluşmaktadır. Bu nedenle bireyler her yerde herkes tarafindan yeterli görülmeyebilirler. Başka deyişle, bireyler belli etkinlikleri yapmakta ya da belli çevrelerde performans göstermede yeterlidirler ve başka alanlarda yetersizlik gösterebilirler. $\mathrm{Bu}$ noktada kişinin kendi yeterliğine ilişkin algısı önem kazanmaktadır. Sosyal yeterlik, birey ve diğerleri arasındaki ilişkide gözlenmekle birlikte, bireyin kendisine ilişkin farkındalığıyla da ilişki içerisindedir. $\mathrm{Bu}$ özelliklerin çocukluk ve ergenlik döneminde kazanılmış olması önemli görülmektedir. Aşağıda sosyal yeterliğe ilişkin literatürde yer alan farklı tanımlara ve açıklamalara yer verilmiştir.

Sosyal yeterliğin basit bir tanımı yapılacak olursa; sosyal yeterlik, olumlu sonuçlar elde ederek çevreyi kontrol eden becerilerin toplamıdır (Connolly ve Bruner, 1974; Foster ve Ritchey, 1979; Gresham, 1981; Hops, 1983; Shure, 1981; akt. Blechman ve diğ., 1985). Sosyal yeterlik, bir yandan taleplere karşı esnek, uyumlu tepkiler geliştirebilme bir yandan da içinde bulunduğu çevrede firsatlar yaratabilme ve onlardan yararlanabilme becerisi (Waters ve Sroufe, 1983) olarak tanımlanırken RoseKrasnor (1997) sosyal yeterliği, kısa ve uzun vadeli gelişimsel ihtiyaçları gidermek üzere geliştirilmiş 
organize davranışlar bütünü olarak tanımlamaktadır (akt. Evirgen, 2010).Başka bir açıklamada da sosyal yeterlik, diğer insanların duygularını anlama, yetişkin müdahalesi olmadan yaşıtlarıyla problemlerini çözebilme, ihtiyaç ve duygularını uygun bir şekilde ifade edebilme yeteneği olarak ifade edilmektedir (Kellam ve diğ., 1975; Macgowan, Nash ve Fraser, 2002; Werthamer-Larsson, Kellam ve Wheeler, 1991; akt. Williams 2004). Sosyal olarak yeterli olan çocukların iyi düzeyde sözel becerileri, geçici durumlara uyum sağlama ve duygu düzenleme becerilerine sahip oldukları da belirtilmektedir (Mendez, Fantuzzo ve Cicchetti, 2002; akt. Oades-Sese, Esquivel, Kaliski, ve Maniatis, 2011). Owens ve Johnston-Rodriguez (2010) ise, sosyal yeterliği, ergenlerin okulda sosyal etkileşimde başarılı olabilmeleri için gerekli olan sosyal, duygusal, bilişsel beceriler ve davranışlar olarak tanımlamaktadırlar.

Semrud-Clikeman'a (2007) göre sosyal yeterlik, bir durumla ilgili olarak başkasının bakış açısını alabilme becerisidir. Sosyal yeterlik kavramı sosyal beceriler, sosyal etkileşim ve kişilerarası iletişimi kapsar iken sosyal beceriler, tekrarlanabilen ve amaç yönelimli davranışları varsayar ve sosyal etkileşim, sözel olmayan iletişim ve diğer kişiyle olan etkileşimini ifade eder. Harvilchuck-Laurenson (1997) de buna benzer olarak sosyal yeterliğin bir bireyin amaçlarına ulaşma ya da bunun için çaba gösterme yeteneğine işaret ettiğini ve kişinin sosyal yeterlik düzeyinin, büyük ölçüde sosyal problem çözme becerileri ve algılanan sosyal destek özelliklerine dayandığını ifade etmiştir. Sosyal problem çözme ise, birtakım yetenekleri gerektirir. İlk olarak birey, problemleri potansiyel olarak kendi kontrolünde görmelidir (Rhodes ve Jason, 1990). Daha sonra birey, problemleri çözmek için farklı çözüm yolları düşünebilmelidir. Bireyin sonuçları değerlendirebilmesi ve kendi özellikleriyle paralel olarak çözüm adımlarını belirlemesi de bu süreç dahilindedir.

Kişilerarası görevleri başarmada ve diğerlerinin yanıtlarını işlemede yetenekli olma (Weinstein 1969); kültürel olarak tanımlanmış görevleri yerine getirmede yetenekli olma (Ogbu 1981); eş zamanlı olarak zamanla ve düzeni bozmadan diğ.,yle olumlu ilişkilerini korurken sosyal etkileşim içinde kişisel hedeflerini başarma (Robin ve Rose-Krasnor, 1992); belirli sosyal beceriler temelinde başkalarıyla etkili bir şekilde etkileşim içinde olma (Baron ve Markman, 2000); başkalarıyla sosyal olarak kabul edilen ve değerli olan, aynı zamanda kişisel olarak yararlı veya ilk olarak başkalarına yararlı olan özel yollarla verilen sosyal bir bağlam içinde etkileşim içinde olabilme yeteneği (Ryan ve Shim, 2006; akt. Pavliga, 2008) sosyal yeterliğin göstergeleri olarak tanımlanmaktadır. Goldberg (1977) sosyal yeterlik gelişiminin başlangıcıyla ilgili bir model önermiştir. Bu modele göre; çocuğun akranlarıyla ve yetişkin bakım verenlerle olası deneyimler yaratmadaki becerisi, sosyal yeterlik gelişiminin merkezidir. Goldberg 'olasılık' (contingency) kavramını çocukların diğerlerine olan tepkilerini okuyabilmesi, okunabilir ve tahmin edilebilir davranışsal ipuçlarını görebilmesi, diğerlerinden tepki alması (ilgi, yardım ve oyun) ve tatmin edici duyguları ve deneyimleri başlatması olarak tanımlamaktadır (akt. Carson, Wagner ve Schultz, 2001).

Bunlara ek olarak daha kapsamlı bir açıklama (Craig, 2000; akt. Evirgen, 2010) yapılmış ve sosyal yeterliği yüksek olan kişilerin, sosyal değerlerin benimsenmesi (ilgi gösterme, yardımseverlik, dürüstlük, eşitlik, sosyal adalet, sorumluluk); kişiler arası beceriler (karşılıklı sosyal destek, işbirliği içeren ilişkiler, duygu düşünce ihtiyaç temelinde iletişim kurma, sosyal ortama uygun davranışlar sergileme, empati, çatışmalara uzlaşmacı bir tavır sergileme); kendini düzenleme (dürtü kontrolü, kendini gözlemleme, zevk veren durumları erteleyebilme); planlama ve karar verme becerileri (seçimler yapabilme, problemleri çözebilme, plan yapabilme, planları uygulayabilme, sosyal hedeflere uygun harekete geçebilme); kültürel yeterlik (farklı 1rk ve etnik kökenlere sayg1 gösterme, onlarla iletişime geçebilme, sosyal adalete uygun davranma, haksız davranışların farkında olma); olumlu kimlik duygusu kazanımı (kişisel güç, yeterlik duygusu, amaca sahip olma, kişisel değerlere sahip olma, olumlu bir gelecek beklentisi) gibi becerileri taşımaları gerektiğini ifade etmiş̧lerdir.

\section{Araştırmanın Amact}

Yukarıda verilen bilgiler 1şığında sosyal yeterlik algısı yüksek olan ergenlerin kolay ilişki kurabilen ve sürdürebilen, empatik olan, diğer insanlara karşı duyarlı, yakın ilişkileri olan ve bunları sürdürebilen, duygularının farkında olan, sözel ve sözel olmayan mesajlara duyarlı olan, kendini kabul düzeyleri 
yüksek olan, sosyal becerilerde yeterli olan vb. özelliklere sahip olan gençler oldukları söylenebilir. Sonuç olarak, olumlu nitelikler olarak ele alınan akademik ve sosyal yeterlik algısı, ergenleri birçok risk faktörüne karşı da koruyucu bir nitelik taşımaktadır. Bu bağlamda yeterlik özelliğinin anlaşılması önemli görülmektedir. Türkiye'deki literatüre bakıldığında bireylerin yeterlik algılarını ölçmeye yarayan ölçeklerin sınırlı sayıda olduğu görülmüştür. Bunlardan biri olan Öz-Etkililik-Yeterlik Ölçeği, Gözüm ve Aksayan (1999) tarafından öğretmenler üzerinde Türkiyeye uyarlanmıştır. Ölçek yetişkinlere uygulanabilmekte ve bireyin genel öz-etkililik-yeterlik algısını ölçmek amaçlanmaktadır. Aynı amaçla uyarlanan Genel Özyeterlik Ölçeği de 18 yaş üstü bireylere uygulanabilen bir ölçektir (Yıldırım ve İlhan, 2010). Aypay (2010) tarafından uyarlanan Genel Özyeterlik Ölçeği de diğerleri gibi benzer şekilde yetişkinlere uygulanmaktadır. Bu ölçeklerin yanı sıra bireylerin fen, bilgisayar, matematik gibi tek bir alana (Iş̧ksal ve Aşkar, 2003; Akkoyunlu, Orhan ve Umay, 2005; Ekici, 2005; Günhan ve Başer, 2007) veya öğretmenlik gibi tek bir mesleğe (Çapri ve Kan, 2006) yönelik yeterlik algılarını ölçmeye yarayan ölçeklerin uyarlandığı veya geliştirildiği görülmektedir. Bununla birlikte ergenlerin akademik ve sosyal yeterliklerini ölçen bir ölçeğe ise rastlanmamıştır.

Bu bilgiler ışığında bu çalışmada geliştirilen Yeterlik Algısı Ölçeği'nde (YAÖ) bireylerin kendilerine yönelik algılarını içeren maddelere yer verilmiş ve YAÖ'nin kuramsal yapısı Achenbach ve Edelbrock'un (1979) açıklamalarına dayanarak oluşturulmuştur. Bu çalışmada ergenlik dönemini kapsayan lise öğrencilerine yönelik olarak bu özelliklerin ölçülebilmesi amaciyla Likert tipi bir ölçeğin geliştirilmesi, bu yolla literatüre ve eğitim alanındaki uygulayıcıların çalışmalarına katkı sağlanması amaçlanmıştır.

\section{YÖNTEM}

\section{Çalışma Grupları}

Yeterlik Algısı Ölçeğini geliştirme çalışmaları 1) ölçeğin hazırlandığı, 2) ölçek revizyonun yapıldı̆̆ı ve 3) test - tekrar test güvenirliğinin incelendiği olmak üzere üç çalışma grubu üzerinde yapılmıştır. Aşağıda bu üç çalışma grubuna ait demografik bilgiler verilmiştir.

\section{Çalışma grubu 1: YAÖ’nin geliştirilmesi}

Yeterlik Algısı Ölçeği taslak formu, 2011-2012 eğitim ve öğretim yılında Ankara ili Milli Eğitim Müdürlüğü’ne bağlı üç lisede toplam 372 öğrenciye uygulanmıştır. Öğrencilerin seçiminde uygun örnekleme yöntemi kullanılmıştır. Öğrencilerin sınıf düzeylerine ve cinsiyetlerine ilişkin bilgiler Tablo 1 'de verilmiştir.

Tablo 1. Katılımcıların Demografik Özellikleri

\begin{tabular}{lccccc}
\hline Kişiler & 9. Sınıf & 10.Sınıf & 11.Sınıf & 12.Sınıf & Toplam \\
\hline Kadın & 34 & 69 & 44 & 48 & 195 \\
Erkek & 44 & 59 & 29 & 45 & 177 \\
Toplam & 78 & 128 & 73 & 93 & 372 \\
\hline
\end{tabular}

Tablo 1'de görüldüğü gibi, katılımcıların 195'i kız (\% 52), 177'si erkektir (\% 48). Dokuzuncu (\% 21) ve on birinci (\% 20) sınıflara devam edenlerin sayısı yaklaşık 70; onuncu sınıfa devam edenlerin 128 (\% 34), on ikinci sınıfa devam edenlerin 93'tür (\% 25). Tablodan da izlendiği gibi, öğrencilerin sınıf ve cinsiyetleri bakımından yeterli düzeyde çalışma grubunda temsil edildikleri söylenebilir. Örneklem büyüklügünün belirlenmesinde faktör yükleri ve faktörlerin maddelerdeki açıkladıkları toplam varyanslar (communality) ve ölçekteki madde sayısı göz önünde bulundurulmuştur (Costello ve Osborne, 2005; Winter, Dodou ve Wieringa, 2009; MacCallum, Wideman, Zhang ve Hong, 1999; Stevens, 2009; Tabachnick ve Fidell, 2007). 


\section{Çalışma grubu 2: YAÖ’nin gözden geçirilmesi (revizyon)}

Yeterlik Algısı Ölçeği'nin gözden geçirilmiş versiyonu, 2012-2013 eğitim ve öğretim yılında Ankara ili Milli Eğitim Müdürlüğü'ne bağlı ve ilk çalışmaya katılan okullardan ayrı, dört lisede toplam 668 öğrenciye uygulanmıştır. Araştırma grubuna katılan öğrencilere ait bilgiler Tablo 2'de verilmiştir.

Tablo 2. Katılımcıların Demografik Özellikleri

\begin{tabular}{lccccc}
\hline Kişiler & 9.Sınıf & 10.Sınıf & 11.Sınıf & 12.Sınıf & Toplam \\
\hline Kadın & 82 & 105 & 79 & 94 & 360 \\
Erkek & 70 & 104 & 74 & 60 & 308 \\
Toplam & 152 & 209 & 153 & 154 & 668 \\
\hline
\end{tabular}

Tablo 2'de görüldüğ̈ gibi, katılımcıların 360’ı kız (\% 53.9), 308'i erkektir (\% 46.1). Farklı sınıflara devam edenlerin oranları \% 22.8 ile \% 31.3 arasindadır. Bu gruptan elde edilen veriler rastgele yöntemle ikiye bölünmüş, 147 kişilik bir grupta ( 83 kız, 64 erkek) betimleyici faktör analizi; geriye kalan 521 kişilik grupta ( 277 kız, 244 erkek) ise doğrulayıcı faktör analizi yapılmıştır.

\section{Çalışma grubu 3: YAÖO Test tekrar test güvenirliği}

Test tekrar test güvenirliği, 2011- 2012 eğitim ve öğretim yılında Ankara ili Mamak ilçe Milli Eğitim Müdürlüğüne bağlı bir liseden seçilen üç sınıfta yapılmıştır. Veriler iki hafta ara ile toplanmıştır. Uygulamaya katılanların 38'i kız, 37'si erkektir. Ayrıca öğrencilerin 53'ü lise iki, 22'si ise lise üçüncü sinifa devam etmektedir.

\section{Veri Toplama Aracı}

$\mathrm{Bu}$ çalışmada veri toplama aracı olarak çalışmada geliştirilen Yeterlik Algısı Ölçeği ile Kişisel Bilgi Formu kullanılmıştır. Makalenin genelinde Yeterlik Algısı Ölçeği’ne ilişkin bilgiler sunulmaktadır. Araştırmacılar tarafından geliştirilen Kişisel Bilgi Formu aracılığıyla çalışma gruplarına ait demografik veriler elde edilmiştir.

\section{Verilerin Analizi ve İslem Yolu}

Yeterlik Algısı Ölçeği rasyonel yaklaşıma dayalı olarak iki aşamada geliştirilmiştir. İlk aşamada literatür taraması yapılmış, madde havuzu meydana getirilmiştir. Araştırma ekibi yeterlik algısı literatürüne uygun maddeleri bireysel olarak hazırlamış, daha sonra bu ekip bir araya gelerek madde havuzundan aynı özelliğe yönelik en uygun ifadeleri seçerek ya da ifade düzeltmesi yaparak 43 maddeden oluşan taslak formu oluşturmuşlardır. Bu form beşli Likert derecelendirmesine uygun şekilde ("Tamamen Uygun", "Uygun", "Kısmen Uygun", "Uygun Değil", "Hiç Uygun Değill") düzenlenmiştir. Daha sonra Psikolojik Danışma ve Rehberlik alanından üç, Eğitimde Ölçme ve Değerlendirme alanından bir uzmandan maddelerin uygunluğu konusunda görüş alınmıştır. Uzmanların önerileri doğrultusunda forma üç yeni madde daha eklenerek, 46 maddelik form ifadelerin anlaşılabilirliğini ve yanıtlanmanın kolaylığını kontrol etmek amacıyla 26 lise öğrencisine uygulanmıştır. Maddelerin öğrenciler tarafından kolaylıkla anlaşılabildiği görülmüş, ardından uygulamaya geçilmiştir. Çalışmanın birinci grubu olan 372 öğrenciden elde edilen ölçümlerin geçerliği betimleyici (exploratory) faktör analizi yapılarak incelenmiştir. Ölçümlerin güvenirliği ise iç tutarlık katsayıları (Cronbach alfa ve tabakalanmış alfa) hesaplanarak test edilmiştir. 372 kişilik veri setinde, betimleyici faktör analizi yapılmadan önce normallik, doğrusallık, aykırı gözlem, çoklu bağlantı, örneklem büyüklüğü ve eksik değer varsayımları gözden geçirilmiş, verilerin bu varsayımları karşıladığ1 gözlemlenmiştir (Costello ve Osborne 2005; Winter, Dodou ve Wieringa, 2009; Fabrigar, Wegener, MacCallum ve Strahan, 1999; Hair, Black, Babin ve Anderson, 2010; Kline, 2010; 
MacCallum, Wideman, Zhang ve Hong, 1999; Pedhazur ve Schmelkin, 1991; Stevens, 2009; Tabachnick ve Fidell, 2007).Madde puanlarının hiçbirinde eksik değer oranı \%5'i aşmadığı; eksik değerlerin maddeler ve kişiler arasında rasgele dağıldıkları görülmüştür. Madde puanlarının her birinde (univariate) normallik, eğiklik ve basıklık katsayılarıyla ve P-P grafikle; maddelerin doğrusal bileşimlerindeki (multivariate) normallik Mardia'nın asimetrik eğiklik ve basıklık katsayılarıyla incelenmiştir (Kline, 2010). Maddeler arasındaki doğrusallık rasgele seçilen maddeler sarasında çizilen saçılma grafikleriyle değerlendirilmiştir. Madde dağılımlarının her birinde aykırı değerler (outlier) z puanlarıyla; doğrusal bileşimlerindeki aykırı puanlar Mahalanobis Uzaklık Testiyle $\left(\chi^{2}\right)$ gözden geçirilmiştir. Bu inceleme sonunda 9 univariate, 3 de multivariate aykırı değer veri setinden çıkarılmıştır. Ayrıca univariate çoklu bağlantı (Collinearity) Pearson korelasyon; multivariate çoklu bağlantı (singularity) Tolerans ve VIF değerleri incelenerek araştırılmıştır. Madde puanları 1-5 arasında derecelendirildiğinden, betimleyici faktör analizi polychoric korelasyon katsayıları üzerinde paralel ve map testler yoluyla principal axis faktör elde etme yöntemi (multivariate normallik sayıltısı ihlal edildiğinden (Fabrigar, Wegener, MacCallum ve Strahan, 1999), direct oblimin eksen döndürme tekniği kullanılarak gerçekleştirilmiştir.

İlk aşamada betimleyici faktör analizi sonucu, madde kompleksliği, düşük faktör yükleri ve maddenin ölçtügü özellik bakımından ait olması beklenen boyutta yer almaması nedenleriyle taslak formda yer alan 46 maddeden 14'ü çıkarılmıştır. Bu işlem sırasında kapsam geçerliği göz önünde bulundurularak, sosyal boyutta yer alan, özellikle faktör yükü düşük sekiz madde daha net ifade edilmiştir. Yeterlik Algısı Ölçeği, ikinci aşamada 668 öğrenciden oluşan, ilk uygulamadaki katılımcılara benzer başka bir örnekleme uygulanmıştır. İlk uygulamadan elde edilen sonuçlara dayalı olarak sonradan düzenlenen yeni maddelerle ölçeğin faktör yapısının kısmen değişmiş olabileceği düşünülmüş, bu örneklemden rastgele seçilen 147 gözlem (yaklaşık madde sayısı * 5 kişi) üzerinde betimleyici faktör analizi tekrarlanmıştır. Betimleyici faktör analizinden elde edilen bulguların genellenebilirliği ise kalan 521 kişilik veri setinde doğrulayıcı faktör analizi yapılarak test edilmiştir. Verilerin çözümlenmesinde Factor 8.02 ve Lisrel 8.70 paket programları kullanılmış, araştırmada hata payı .05 olarak alınmıştır.

\section{BULGULAR}

\section{YAÖ’nin Gelişstirilmesi}

Yeterlik Algısı Ölçeği taslak formu oluşturulurken sosyal ve akademik yeterlik alanlarına ilişkin maddeler yazılmış ve başlangıçta ölçeğin iki boyutlu olabileceği öngörülmüştür. Boyut sayısı sınırlanmadan yapılan temel bileşenler analizi sonucunda, gerçek verilerden elde edilen özdeğerlerin mavi çizgi, paralel analiz sonucunda elde edilen random özdeğerlerin ise kırmızı çizgi ile gösterildiği özdeğerler grafiği (scree plot) Şekil 1'de verilmiştir:

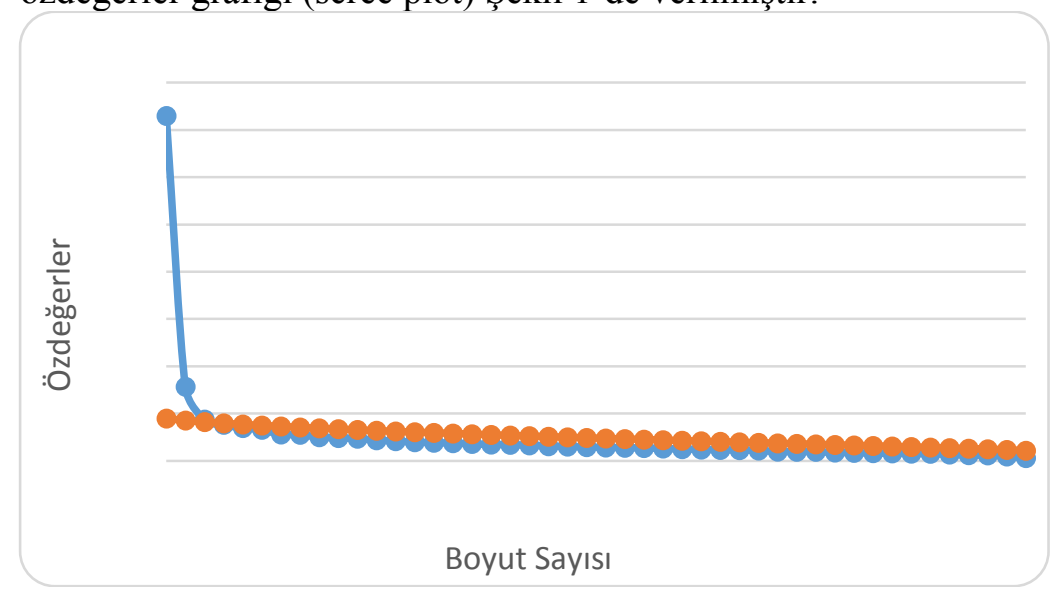

Şekil 1. Scree Plot 
Şekil 1'de, gerçek veri setinde I. özdeğer 15.49, II. özdeğer 3.13 olup random sayılarla üretilen özdeğerlerden yüksektir. Gerçek veri setinde özdeğeri birden büyük (Kaiser kuralı) dokuz boyut bulunmasına karşın, 3. boyutta yaklaşık olarak gerçek ve random özdeğerler aynı düzeydedir. Benzer şekilde, Minimum Avarage Partial Test (MAP) sonucunda ortalama kısmi değerler I. boyut için .011, II. boyut için .007 olarak elde edilmiş, scree plot ve paralel analiz sonuçlarında olduğu gibi 2 boyut önerilmiştir. Buna göre, hem scree plot ve paralel analiz hem de MAP test sonuçlarının, öngörülen boyut sayısını destekledikleri kabul edilmiştir. Bunun üzerine, principal axis faktör elde etme yönteminin ve direct oblimin eksen döndürme tekniğinin kullanıldığı betimleyici faktör analizi yapılmış, Kaiser-Meyer-Olkin (KMO) örnekleme yeterlik değeri .94 olarak önerilen kesme noktasından (.60) yüksek bulunmuştur. Benzer şekilde, Bartlett küresellik testi de istatistiksel bakımdan önemlidir $\left(\chi_{1035}^{2}=7306.2, \mathrm{p}=.00\right.$ bulunmuştur. Madde-faktör korelasyonlarının (yük) belirlenmesinde, çeşitli kaynaklarda verilen kesme değerlerinin ortalaması alınarak, ölçekteki madde sayısının yanı sıra örneklemdeki kişi sayısı da göz önünde bulundurularak, önemli yüklerin ait oldukları boyutta .30 'dan büyük, diğer boyutta ise .25 'ten küçük olması kriteri benimsenmiştir (Hair, Black, Babin ve Anderson 2010; Stevens 2009; Tabachnick ve Fidell 2007; akt. Raunberheim, 2004). Buna göre, I. boyutta 24 (yükler: .40 ile .74); II. boyutta sekiz (yükler: .35 ile .54) olmak üzere 32 maddenin ölçekte kalması gerektiği gözlemlenmiştir. Bu iki boyutun, toplam varyansın \%38'ini açıkladıkları görülmüştür.

\section{Güvenirlik çalışması}

Faktör analizi sonucunda elde edilen boyutlar için iç tutarlık katsayıları (Cronbach alfa) hesaplanmıştır. I. boyutun iç tutarlık katsayısı .94, ortalaması 41.46, standart sapması 14.21'dir. Madde-toplam korelasyon katsayıları .37-.63 arasindadır. Ortalama madde -madde korelasyonu .43 'tür. II. boyutun iç tutarlık katsayıs1 .82 , ortalaması 24.26, standart sapmas1 6.49'dur. Madde toplam korelasyonu $.35-.54$ arasındadır. Ortalama madde -madde korelasyonu .31 'dir. Ölçeğin bütünü için tabakalanmış alfa güvenirlik katsayısı ise .94 olarak hesaplanmıştır.

\section{YAÖ’nin Gözden Geçirilmesi (Revizyon Çalışması)}

\section{Betimleyici faktör analizi sonuçları}

İlk çalışmada, Yeterlik Algısı Ölçeği için madde havuzu oluşturulmuş, bu havuz kullanılarak maddeler arasındaki ilişkiler, betimleyici faktör analizi ile incelenmiştir. Yapılan ilk çalışmada, her iki boyut için yaklaşık eşit sayıda, toplam 46 maddeden oluşan bir değişken seti kullanılmış ancak I. faktörde 25 , II. faktörde ise 8 madde .30 'dan büyük yüke sahip olarak bulunmuştur. Her ne kadar bu haliyle maddeler kuramsal olarak öngörülen boyutlarla yüksek korelasyonlara sahip olsalar da, boyutların madde sayılarında büyük oranda dengesizlik görülmüş, ayrıca sosyal ve akademik boyutlar arasında kuramsal olarak beklenenden daha yüksek korelasyonlar elde edilmiştir. Bu nedenle ölçek geliştirme çalışmasının ikinci aşamasında, bazı maddeler yeniden ifade edilip, yeni maddeler de eklenerek akademik yeterlik boyutu tekrar düzenlenmiştir. İlk çalışmada yüksek yüke sahip sosyal yeterlik maddeleriyle birlikte oluşturulan 32 maddelik yeni form, ilk uygulamadaki örnekleme benzer özellikler taşıyan, ancak önceki çalışma gruplarından başka 668 kişilik bir örnekleme uygulanmıştır. İlk çalışmada, Yeterlik Algısı Ölçeğinin sosyal ve akademik olmak üzere iki yeterlik alanından oluştuğu ortaya konduğundan, ikinci aşamada ilk olarak örneklemin bir bölümünde $(n=147)$ iki boyutlu betimleyici faktör analizi yapılmıştır. Örneklemin geriye kalanı $(n=521)$ için ise doğrulayıcı faktör analizi uygulanmıştır. Betimleyici faktör analizi sonucunda $\mathrm{KMO}=.87$; Bartlett küresellik testi $\mathrm{x}_{496}^{2}=2925.94, \mathrm{p}=.000$ olarak elde edilmiştir. Bu katsayılar maddeler arasındaki ilişkinin faktör analizi için uygun olduğunu göstermektedir. Faktör analizi sonucunda elde edilen faktör yükleri Tablo 1 'de verilmiştir. 
Tablo 3. Yeterlik Alg1sı Ölçeği Madde - Faktör Yükleri

\begin{tabular}{|c|c|c|}
\hline \multirow{2}{*}{ Maddeler } & \multicolumn{2}{|c|}{ Faktör } \\
\hline & Akademik & Sosyal \\
\hline 1. Yeni insanlar tanımaktan hoşlanırım. & & .61 \\
\hline 2. Duygularımı rahatça ifade edebilirim. & & .37 \\
\hline \multicolumn{3}{|l|}{ 3. Başkalarının duygularını kolaylıkla anlayabilirim. } \\
\hline 4. Sosyal etkinlikler düzenlemede başarılıyım. & & .59 \\
\hline 5. Arkadaşlarım arasında sevilen biriyim. & & .61 \\
\hline 6. Grup çalışmalarında işbirliği yapabilirim. & & .52 \\
\hline 7. İnsanlarla uzun süreli ilişkiler kurabilirim. & & .62 \\
\hline 8. Arkadaşlarımla zaman geçirmekten hoşlanırım. & & .67 \\
\hline 9. Başkalarıyla kolayca iletişim kurabilirim. & & .67 \\
\hline 10. Başkalarının duygularına önem veririm. & & .50 \\
\hline 11. S1k1 dostluklar kurabilirim. & & .68 \\
\hline 12. Arkadaşlarım tarafindan etkinliklere davet edilirim. & & .60 \\
\hline \multicolumn{3}{|l|}{ 13. Arkadaşlarımın isteklerine gerektiğinde hayır diyebilirim. } \\
\hline 14. Sinema, tiyatro gibi etkinliklere arkadaşlarımla giderim. & & .46 \\
\hline 15. Arkadaşlarım ihtiyaç duyduklarında bana danışırlar. & & .56 \\
\hline 16. Arkadaşlık ilişkilerime önem veririm. & & .73 \\
\hline 17. Derslerle ilgili soruları yanıtlamakta istekli davranırım. & .63 & \\
\hline 18. Yeni ders konularını zorlanmadan öğrenebileceğimi düşünürüm. & .65 & \\
\hline 19. Başarılı bir öğrenciyim. & .70 & \\
\hline 20. Sınavlara iyi hazırlanırım. & .70 & \\
\hline 21. Ödevlerimi öğrenme hevesiyle yaparım. & .68 & \\
\hline 22.Ders sonrasında da öğrendiklerim üzerinde düşünürüm. & .67 & \\
\hline 23. Derste öğrendiklerimi arkadaşlarımla tartışırım. & .53 & \\
\hline 24. Dersleri dikkatle dinlerim. & .82 & \\
\hline 25. Başkalarının yardımı olmadan ödevlerimi yapabilirim. & .54 & \\
\hline 26. Ödevlerimle gurur duyarım. & .54 & \\
\hline 27. Dersi derste öğrenirim. & .68 & \\
\hline 28. Akademik başarımdan memnunum. & .45 & \\
\hline 29. Derslerde sorulan zor soruları yanttlayabilirim. & .49 & \\
\hline 30. Derslerde yeni bir şeyler öğrenmeyi önemli bulurum. & .71 & \\
\hline 31. Derslerle ilgili bilgilerimin yeterliğine güvenirim. & .61 & \\
\hline 32. Ders konularını çeşitli kaynaklardan araştırırım. & .56 & \\
\hline
\end{tabular}

Madde - Faktör ilişkisi (yük) kesme noktası .36

Tablo 3'de görüldüğü gibi, akademik yeterlik boyutunda yer alan maddelerin yükleri .43 - .75; sosyal yeterlik boyutundaki maddelerin yükleri .37-.65 arasındadır. Stevens (2009) 200 kişilik bir örneklemde, madde- faktör korelasyonları için kesme noktasının .36 olması gerektiğini belirtmektedir. Buna göre, 3. ve 13. maddelere ilişkin faktör yükleri bu sınırın altında kalmaktadır. Bununla birlikte, madde 3 ve 13 için ilk uygulamadaki faktör yükleri sırasıyla .57 ve .54 'tür. İki uygulamada faktör yükleri arasındaki bu değişkenlik, örneklem farklılığına bağlanmış ve bu durum bulguların genellenebilirliğini sınırladığından veri setinden çıkarılmaları düşünülmüştür. İki boyutlu yapıya ilişkin açıklanan toplam varyans .37 (özdeğerler sırasıyla 7.99 ve 3.81); söz konusu maddelerin veri setinden çıkarılmasıyla tekrarlanan faktör analizi sonucunda açıklanan toplam varyans .39 (özdeğerler sırasıyla 7.83 ve 3.76 ) bulunmuştur. $\mathrm{m} 3$ ve $\mathrm{m} 13$ veri setinden çıarıldıklarında, sosyal yeterlik boyutunda yer alan maddeler için madde toplam korelasyonları .30 - .67 arasında olup, iç tutarlık katsayısı .87 'dir. Bu katsayılar, iki maddenin veri setinden çıkarılmasının güvenirliği azaltmadığını göstermektedir. Bu bulgulardan hareketle ilgili maddeler veri setinden çıkarılmaya karar verilmiştir. Tekrarlanan betimleyici faktör analizine ilişkin madde-faktör ilişkileri Şekil 1'de sunulmuştur. 


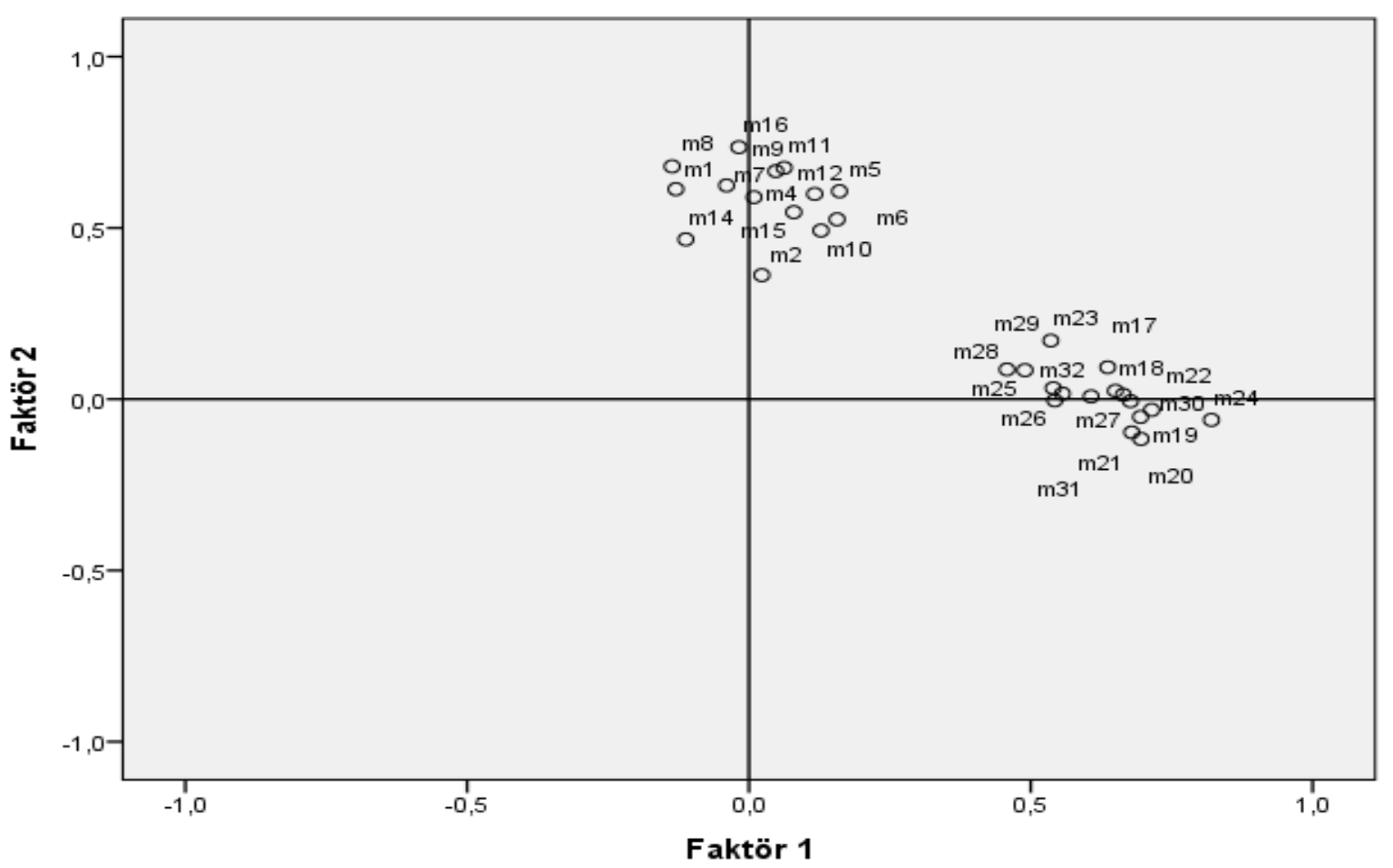

Şekil 2. Madde - Faktör Yükleri Saçılma Grafiği

Şekil 2'de görüldügü gibi, maddeler eksen çizgileri üzerinde kümelenmektedir. Bu durum boyutlar arasındaki ilişkilerin düşük olduğunu göstermektedir (faktörler arası $\mathrm{r}=.30$ ). Ayrıca maddeler orijin noktasından $(0,0)$ uzakta yer almaktadır. Bu da maddelerin ait oldukları faktörde yüksek yüke sahip oldukları anlamına gelmektedir. Bu sonuçlar 1şığında, Yeterlik Algısı Ölçeği akademik boyutta 16 madde, sosyal boyutta 14 madde olmak üzere toplam 30 maddeden oluşturulmuştur.

\section{Güvenirlik çalışması}

Bir bütün olarak ölçeğin iç tutarlık katsayısı (tabakalanmış alfa) .91 olarak hesaplanmıştır. Akademik yeterlik boyutunda yer alan maddeler için madde toplam korelasyonları .47-.73 arasında olup, iç tutarlık katsayısı (Cronbach alfa) .90 'dır. Sosyal yeterlik boyutunda yer alan maddeler için madde toplam korelasyonları .11 - .67 arasında olup, iç tutarlık katsayısı (Cronbach alfa) .86'dır.

\section{Doğrulayıcı faktör analizi sonuçları}

Betimleyici faktör analiziyle elde edilen sonuçların benzer başka bir örneklemdeki $(n=521)$ geçerliği doğrulayıcı faktör analizi yapılarak incelenmiş, sonuçlar Şekil 3’te verilmiştir. 


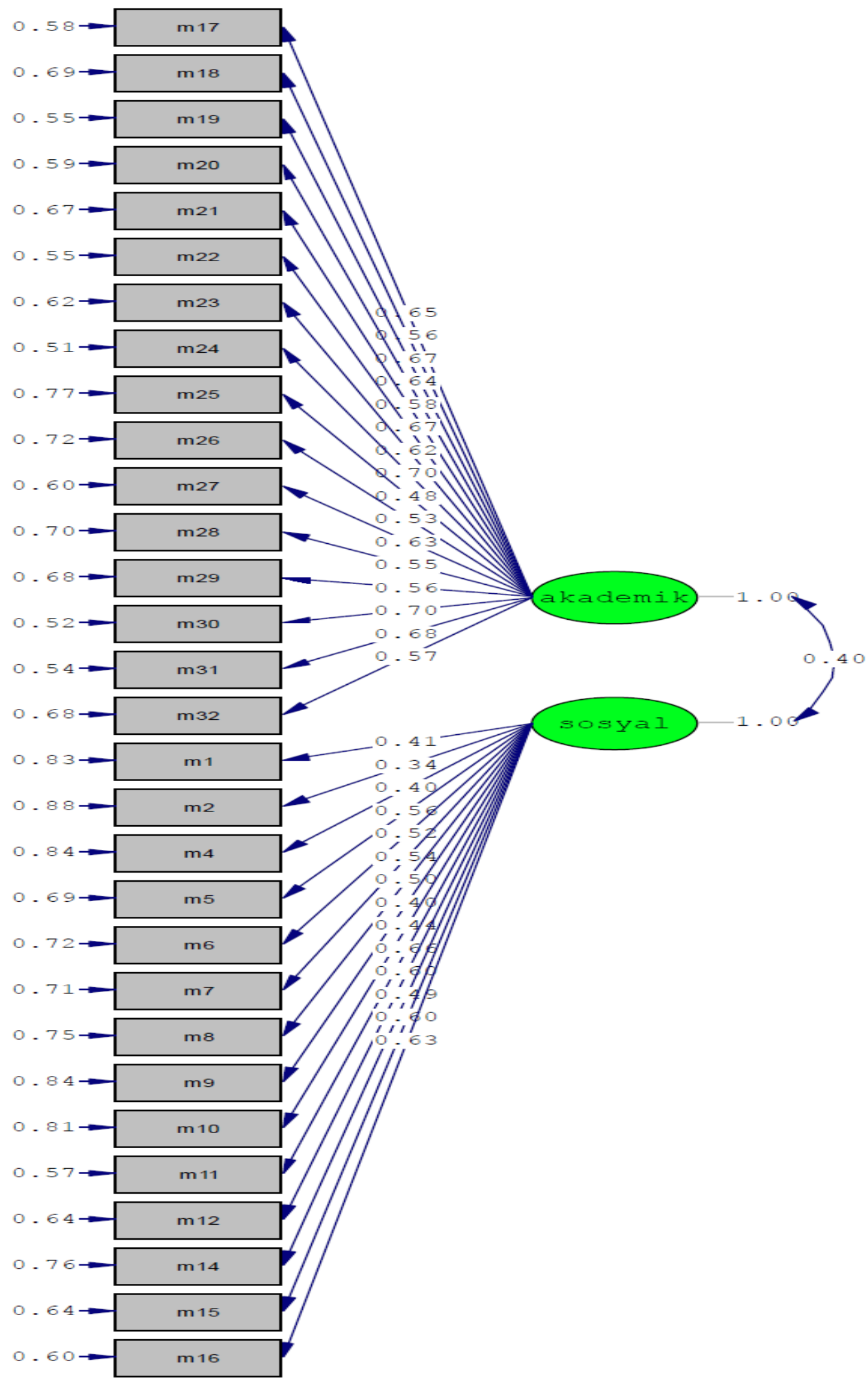

Şekil 3. İki Boyutlu Yeterlik Algısı Ölçeği Doğrulayıcı Faktör Analizi Sonuçları

Şekil 3'te de görüldüğü gibi, standartlaştırılmış regresyon katsayıları akademik yeterlik için .48-.70; sosyal yeterlik için $.34-.66$ arasındadır. I. boyutun açıkladığı ortalama varyans (AVE) .38; II. boyutun 
açıkladığı .25 'tir. I. boyutta standartlaştırılmış regresyon ağırlıkları madde 25 dışında $>.50$ iken, II. boyutta 6 maddenin standartlaştırılmış ağırlığ 1.50 'nin altındadır. Bileşik (composite) güvenirlik I. boyut için .91; II. boyut için .83 olup, her ikisi de kendi AVE değerlerinden daha yüksektir. AVE değerleri $<.50$ olmasına karşın, Kline (2010) .30 civarındaki standartlaştııılmış ağırlıkların orta; .50 ve üzerindeki ağırlıkların ise büyük etki büyüklüklerini yansıttığını belirtmektedir. Buna göre, her iki boyutta yer alan maddeler, ait oldukları boyutların oldukça geçerli göstergeleridir. Dolayısıyla bu sonuçlar benzeme (convergent) geçerliğinin kısmen karşılandığını göstermektedir. Ayrıca faktörler arasındaki varyans .16 olup AVE değerlerinden düşüktür. Buna ek olarak, sosyal ve akademik yeterlik boyutları arasındaki korelasyon .40 olup, bu katsayıya ilişkin standart hata .04 'tür. Buna göre, iki değişken arasındaki ilişkinin güven aralığı $.40 \pm 1.96^{*} .04=.40 \pm .08=.32-.48^{\prime}$ 'dir. Bu aralığın 1'i kapsamaması, Yeterlik Algısı Ölçeği'nin tek boyutlu bir yapıya sahip olmadığı, başka deyişle ayırma (discriminant) geçerliğine sahip olduğu düşüncesini desteklemektedir. Bu açıklamalardan ayrı olarak, modelin genel uyum katsayıları, hipotez modelin kabul edilebilir düzeyde uyuma sahip olduğunu göstermektedir $\left(x_{404}^{2}=1873.78, \mathrm{p}=.00\right.$, Normed $x^{2}=4.64$; CFI= .92; RMSEA= .08 (.07-.09); SRMR= .07). Büyük örneklemlerde $x^{2}$ testi önemli bulunduğundan, ek uyum istatistikleri verilmektedir. $x^{2}$ 'nin serbestlik derecesine bölünmesiyle elde edilen Normed $x^{2}$ testinin 2-5 arasında olması (Tabachnick ve Fidell 2007); CFI'nın .90'dan büyük, RMSEA'nın da .07'den küçük olması istenmektedir (Bollen 1989; Hair, Black, Babin ve Anderson 2010; Kline 2010; MacCallum, Browne ve Sugawara 1996). Dolayısıyla bu görüşler, modele ilişkin katsayıların yeterli olduğuna kanıt sayılabilir.

\section{Güvenirlik çalışması}

Doğrulayıcı faktör analizinin uygulandığı veri setinde iç tutarlık katsayıları (Cronbach alfa) sosyal yeterlik için .82 , akademik yeterlik için .90 , testin bütünü için tabakalanmış alfa .91 bulunmuştur. Madde toplam korelasyonları sirasiyla .37 - .53 ve .46 - .65 arasındadır.

$\mathrm{Bu}$ çalışmadan ayrı olarak, test tekrar test güvenirlik katsayıları sosyal yeterlik için (r) .79, akademik yeterlik için (r) .82 olarak bulunmuştur. Bununla birlikte, her iki ölçüm de ölçme hataları içermektedir. Buna göre, test tekrar test güvenirlikleri için düzeltilmiş korelasyon katsayıları (r) sosyal yeterlik için .94; akademik yeterlik için $.90^{`}$ dır. I ve II. uygulamada sosyal yeterlik için iç tutarlık katsayıları .82 ve .86 ; akademik yeterlik için .90 ve .93 'tür.

\section{SONUÇ ve TARTIŞMA}

$\mathrm{Bu}$ çalışmada lise öğrencilerinin akademik ve sosyal yeterlik algısını ölçmek amacıyla Yeterlik Algısı Ölçeği geliştirilmiştir. Ölçekten elde edilen ölçümlerin geçerlik çalışmaları için betimleyici ve doğrulayıcı faktör analizi; güvenirlik çalı̧̧ması için ise Cronbach ve tabakalı alfa iç tutarlılık katsayıları ile test - tekrar test yöntemleri kullanılmıştır.

Yeterlik Algısı Ölçeği taslak formu oluşturulurken sosyal ve akademik yeterlik alanlarına ilişkin maddeler yazılmış ve başlangıçta ölçeğin kuramsal açıklamalara dayalı olarak (Achenbach ve Edelbrock, 1979) iki boyutlu olabileceği öngörülmüştür. İlk araştırma grubundan $(n=372)$ elde edilen veriler üzerinde çeşitli faktör belirleme yöntemlerinin (özdeğer grafiği, paralel ve map test vb.) denendiği betimleyici faktör analizi yapılmıştır. Analiz sonuçları öngörülen yapıyla uyumlu iki boyutun, maddeler arası ilişkileri açıklamakta yeterli olduğunu göstermiştir. Bununla birlikte, boyutların madde sayıları arasında büyük oranda dengesizlik (25'e 11) görülmüş, ayrıca her iki boyut arasında kuramsal olarak beklenenden daha yüksek korelasyonlar elde edilmiştir. Bu gerekçe ile ölçek geliştirme çalışmasında revizyona gidilmiştir. Revizyon aşamasında akademik yeterlik boyutunda bazı maddeler yeniden ifade edilip, yeni maddeler de eklenerek YAÖ araştırmacılar tarafından tekrar düzenlenmiştir. Daha sonra, 32 maddeden oluşan yeni form kullanılarak geçerlik ve güvenirlik çalışmaları tekrarlanmıştır. YAÖ'nin yapısı değiştiğinden, ikinci araştırma grubundan $(n=668)$ elde edilen veriler ikiye bölünmüş; bu gruplardan ilkinde $(n=147)$ betimleyici faktör analizi tekrarlanmış, ikincisinde ise $(n=521)$ doğrulayıcı faktör analizi yapılmıştır. Her iki analiz sonucunda, kuramsal 
yapının veri setindeki gözlenen ilişkileri yeterince açıkladığı ve modellerin kabul edilebilir düzeyde geçerlik katsayılarına sahip oldukları görülmüştür (Bollen 1989; Hair, Black, Babin ve Anderson, 2010; Kline, 2010; MacCallum, Browne ve Sugawara, 1996; Tabachnick ve Fidell, 2007). Buna göre, YAÖ kullanılarak araştırma gruplarından elde edilen ölçümlerin geçerli oldukları, farklı örneklemlerde akademik ve sosyal yeterlik boyutlarının tutarlı bir şekilde elde edildiği, dolayısıyla bu bulgunun genellenebileceği ifade edilebilir.

Ölçümlerin güvenirlikleri Cronbach alfa katsayısı ve test-tekrar test güvenirlik katsayıları hesaplanarak incelenmiştir. Yapılan bu analizlerde elde edilen katsayılar .79 ile .94 arasında değişmiştir ve literatüre bakıldığında güvenirlik katsayısının ne kadar olması gerektiğinin nasıl kullanılacağına bağlı olduğu bununla birlikte, yordama ve yapı geçerliği çalışmalarında .70 düzeyinde güvenirliğe sahip olan araçların kullanılmasının uygun olduğu belirtilmektedir (Nunnally ve Berstein, 1994). Bu bağlamda YAÖ’den elde edilen ölçümlerin güvenilir olduğu ileri sürülebilir.

Sonuç olarak, 30 maddeden oluşan Yeterlik Algısı Ölçeği, lise öğrencilerinin akademik ve sosyal yeterlik algılarını ölçmek amacıyla kullanılabilecek düzeydedir. Ölçekten alınan yüksek puan, öğrencilerin kendilerini yeterli algıladığını, alınan düşük puan ise öğrencilerin yeterlik algılarının düşük olduğuna işaret etmektedir.

Çalışma kapsamında elde edilen bulgular çerçevesinde uygulayıcı ve araştırmacılar, Yeterlik Algısı Ölçeği'nden çeşitli amaçlarla kullanabilirler. Lisede çalışan psikolojik danışmanlar, öğrencilerin sosyal ve akademik yeterlik algılarını belirlemek amacıyla yapacakları bireysel ve grup değerlendirmelerinde ölçeğin tümünden ve alt boyutlarından yararlanabilirler. Ölçek aracılığıyla yeterlik algısı düşük öğrenciler belirlenerek bu öğrencilerin yeterlik algılarını arttırmaya yönelik uygulamalar yapılabilir. Ancak geliştirilen ölçme aracının öğrencilerin yeterliklerine ilişkin kendi algılarını belirlemeye yönelik olduğu, dolayısıyla ortaya çıkan sonuçların öznellik içerebileceği dikkate alınmalıdır. Araştırmacılar tarafından Yeterlik Algısı Ölçeğinin cinsiyete ve sınıf düzeyine göre norm tabloları oluşturulabilir. Ölçeğin geçerlik ve güvenirlik çalışmaları ortaokul ve üniversite ögrencilerinde, çeşitli özel gruplarda (yetiştirme yurdunda kalanlar, farklı lise türlerinde, psikolojik danışma merkezine başvuran danışanlarda vb.) tekrarlanabilir. Ayrıca, bu çalışmada ölçeğin geçerlik çalışmaları kapsamında açıklayıcı ve doğrulayıcı faktör analizi yöntemlerine başvurulmuştur. Farklı geçerlik yöntemleri kullanılarak ölçeğin geçerliğine ilişkin sağlanan kanıtlar artırılabilir.

\section{KAYNAKÇA}

Achenbach, T. M., \& Edelbrock, C. S. (1979). The child behavior profile: II. boys aged 12-16 and girls aged 611 and 12-16. Journal of Consulting and Clinical Psychology, 47 (2), 223-233.

Achenbach, T. M., \& McConaughy, S. H. (1987). Child/adolescent behavioral and emotional problems: Implications of cross-informant correlations for situational specificity. Psychological Bulletin, 101 (2), 213-232.

Achenbach, T., \& Zigler, E. (1963). Social competence and self-image disparity in psychiatric and nonpsychiatric patiens. Journal of Abnormal and Social Psychology, 67 (3), 197-205.

Anderman, E. M., \& Midgley, C. (1997). Changes in achievement goal orientations, perceived academic competence, and grades across the transition to middle-level schools. Contemporary Educational Psychology, 22(3), 269-298.

Blechman, E. A., Tinsley, B., Carella, E. T., \& McEnroe, M. J. (1985). Childhood competence and behavior problems. Journal of Abnormal Psychology, 94 (1), 70-77.

Bollen, K. A. (1989). Structural equations with latent variables. NY: Wiley.

Carson, D. K., Wagner, B. S., \& Schultz, N. W. (2001). Temperament and gender: Correlates of Toddler social competence. Journal of Genetic Psychology, 148 (3), 289-302.

Costello, A. B., \& Osborne, J. W. (2005). Best practices in exploratory factor analysis: four recommendations for getting the most from your analysis. Practical Assessment Research \& Evaluation, 10 (7), 1-9.

Evirgen, N. (2010). Aile içi örüntülerin çocukların algıları açısından incelenmesi. Yüksek lisans tezi, Ankara Üniversitesi, Sosyal Bilimler Enstitüsü, Ankara.

Fabrigar, L. R., Wegener, D. T., MacCallum, R. C., \& Strahan, E. J. (1999). Evaluating the use of exploratory factor analysis in psychological research. Psychological Methods, 4 (3), 272-299.

Hair, J. F., Black, W. C., Babin, B. J., \& Anderson, R. E. (2010) Multivariate data analysis (7 ${ }^{\text {th }}$ ed.). Pearson Company. 
Harter, S. ve Pike, R. (1984). The pictorial scale of perceived competence and social acceptance for young children. Child Development, 55, 1969-1982.

Harvilchuck-Laurenson, J. D. (1997). The relationships of stress, social competence, and health status with adolescent academic achievement. Doctorate thesis, The Johns Hopkins University, Maryland.

Kline, R. B. (2010). Principles and practice of structural equation modeling (3rd ed.). New York: Guilford Press.

MacCallum, R. C., Browne, M. W., \& Sugawara, H. M. (1996). Power analysis and determination of sample size for covariance structure modeling. Psychological Methods, 1, 130-149.

MacCallum, R. C., Widaman, K. F., Zhang, S., \& Hong, S. (1999). Sample size in factor analysis. Psychological Methods, 4, 84-99.

Nunnally, J. C. \& Berstein, I. H. (1994). Psychometric Theory. 3. Edit. McCraw-Hill, Inc. New York.

Oades-Sese, G. V., Esquivel, G. B., Kaliski, P. K., \& Maniatis, L. (2011). A longitudinal study of the social and academic competence of economically disadvantaged bilingual preschool children. Developmental Psychology, 47 (3), 747-764.

Owens, L. A., \& Johnston-Rodriguez, S. (2010). Social competence. International Encyclopedia of Education. [Çevrim-içi: http://www.sciencedirect.com/science/article/pii/B9780080448947011593], Erişim tarihi: 6 Ekim 2012.

Parsons, J. E. (1982). The development of expectancies, attributions, and persistence. University of Michigan Documentaries.

Pavliga, G. K. (2008). Toward a conceptual definition for social competence: An explaratory study. Doctorate thesis, The University of Akron, Ohio, USA.

Pedhazur, E. J., \& Schmelkin, L. P. (1991). Measurement, design, and analysis: An integrated approach . Hillsdale, NJ: Erlbaum.

Phillips, D. (1984). The illusion of incompetence among academically competent children. Child Development, $55,2000-2016$.

Raubenheim, J. (2004). An item selection procedure to maximise scale reliability and validity. SA Journal of Industrial Psychology, 30 (4), 59-64.

Rhodes, J. E., \& Jason, L. A. (1990). A social stress model of substance abuse. Journal of Consulting and Clinical Psychology, 58, 395-401.

Semrud-Clikeman, M. (2007). Social competence in children. USA: Springer Science_Business Media, LLC.

Stevens, J. (2009). Applied multivariate statistics for the social sciences (5th ed.). New York: Routledge Taylor \& Francis Group.

Tabachnick, B. G., \& Fidell, L. S. (2007). Using multivariate statistics (5th ed.). Boston: Pearson, Allyn \& Bacon.

Wentzel, K. R. (1993). Does being good make the grade? Social behavior and academic competence in middle school. Journal of Educational Psychology,85(2), 357.

Williams, S. A. (2004). The academic achievement gap: linkages among behavirol, social and academic competencies. Doctorate thesis, University of North Carolina, Chapel Hill.

Winter, J. C. F. ve Dodou, D., Wieringa, P. A. (2009). Exploratory factor analysis with small sample sizes. Multivariate Behavioral Research, 44 (2), 147-181.

\section{EXTENDED ABSTRACT}

\section{Introduction}

Perceived competence is an important driving force underlying the behavior of individuals. It is stated that competence includes two dimensions as academic and social competence in literature. Academic competence is associated with features such as related not compelling to understand and attend lessons, being pleasure to deal with the lessons outside of school, evaluating the success without criteria of academic averages, expressing his/her potential to be able to do homework, becoming aware of the capabilities as well as school success (Blechman, Tinsley, Carella \& McEnroe, 1985; Harter, 1983; Phillips, 1984). On the other hand, social competence is explained with features such as establishing and maintaining relationships easily, being empathic, sensitivity to other people, emotional awareness, sensitivity to verbal and nonverbal messages, self acceptance, being competent social skills (Owens \& Johnston-Rodriguez, 2010; Pavliga, 2008; Williams, 2004; Semrud-Clikeman, 2007). Therefore, evaluation of the academic and social dimensions of individuals' perceived competence might be deemed necessary. Based on this need, Perceived Competence Scale (PCS) has 
been developed to measure high school students' perceived academic and social competence in Turkey, and the scale development process is explained in this research.

\section{Method}

Scale development studies have been conducted on three separate samples. First study has been conducted on 372 high school students in Ankara. Validity of the measurements, obtained from draft form (consisted of 46 items) prepared by the research group, have been examined by using exploratory factor analysis. The reliability of the measurements have been tested through calculating internal consistency coefficients (Cronbach's alpha and stratified alpha). Factor 8.02 package program has been used to analyze the data.

New form of the scale, consisted of 32 items, which was revised with exploratory factor analysis at the first stage and after that new items were added or some items were taken out, has been carried out to 668 students as an other sample. Basing on the idea that factor structure of new form of the scale could change, exploratory factor analysis has been repeated on 147 data that was chosen randomly from this sample. The generalizability of the findings from exploratory factor analysis has been tested with other 521 persons' data set through confirmatory factor analysis.

\section{Results and Discussion}

As a result of exploratory factor analysis, $\mathrm{KMO}=.87$, Barlett's sphericity test $\mathrm{x}_{496}^{2}=2925.94, p=.000$ has been found. Factor loads of the items in academic competence and social competence dimensions are between respectively as follows: .43-.75, .37-65. Factor loadings are under .40 two items have been taken out of the data set. After the repeated exploratory factor analysis, perceived competence scale has been formed with 16 items for academic dimension, 14 items for social dimension, and 30 items for the whole scale.

Confirmatory factor analysis has been used in the second study to examine the validity of the results that were found in exploratory factor analysis in an other similar sample $(\mathrm{n}=521)$. After all, fit indexes have showed that hypothesis model is in an acceptable level $\left(x_{404}^{2}=1873.78, p=.00\right.$, Normed $x^{2}=$ 4.64; $\mathrm{CFI}=.92 ; \mathrm{RMSEA}=.08(.07-.09)$; $\mathrm{SRMR}=.07)$.

Cronbach's alpha internal consistency coefficient and test-retest methods have been used for reliability analyses. Internal consistency coefficient (stratified alpha) of the scale has been found .91 in the data set which exploratory factor analysis was done with. Item-total correlations for the items in academic competence dimension are between .47 and .73, and internal consistency coefficient (Cronbach's alpha) of the dimension is .90. Item-total correlations for the items in social competence dimension are between .11 and .67, and internal consistency coefficient (Cronbach's alpha) of the dimension is .86. Internal consistency coefficients (Cronbach's alpha) are .82 for social competence, .90 for academic competence, and stratified alpha is .91 for the whole scale in the data set which confirmatory factor analysis was done with. Corrected correlation coefficients (r) for test-retest reliability are .94 for social competence and .90 for academic competence.

As a result, academic competence dimension of the scale has 16 items and social competence dimension has 14 items. Perceived Competence Scale is developed to measure high school students' perceptions about their academic and social competence. If the scores are high, it means students perceive themselves more competent; on the other hand, if the scores are low, it means students' perceptions about themselves less competent.

In the light of this information, Perceived Competence Scale can be used to determine high school students' perceived competence, and assess counseling practices for raising lower perceived competence. In the future, validity and reliability studies can be repeated with adding emotional competence dimension to Perceived Competence Scale. 